\title{
MINERAÇÃO E ÁREAS DE PRESERVAÇÃO PERMANENTES (APPs) EM SANTO ANTÔNIO DE
} PÁDUA - RJ

\section{Mining and Environmental Permanent Preservation Areas (APPs) In Santo Antônio De Pádua - RJ}

\author{
Antônio Soares da Silva \\ Prof. Adjunto do Departamento de Geografia Física do Instituto de Geografia da UERJ \\ Rio de Janeiro/RJ - Brasil \\ antoniossoares@gmail.com
}

Artigo recebido para publicação em 21/03/2011 e aceito para publicação 13/06/2011

RESUMO: $\quad$ O Município de Santo Antônio de Pádua tem na atividade de mineração uma das suas principais atividades econômicas. Entretanto a lavra dos minérios promove uma série de impactos ambientais, além do fato de que algumas mineradoras estarem localizadas em Áreas de Preservação Permanente (APP). O trabalho teve como objetivo mapear as APPs no município de Santo Antônio de Pádua e identificar as mineradoras que operam nestes ambientes. Para o mapeamento das APPs foi utilizado o software ArcGis ${ }^{\circledR}$ da Esri, fotografias aéreas na escala de 1:10.000 e base topográfica da Fundação IBGE na escala de 1:50.000. Para definição das APPs foram utilizados os conceitos apresentados nas resoluções 302 e 303, ambas de 2002, do Conama. Foram mapeadas as APPs de Topo de Morro e Montanha, Linha de Cumeada, Encosta com declividade superior a 45, Nascentes e Faixa Marginal de Corpos Hídricos. As APPs ocupam uma área de 212,288 km² o que corresponde a 34,782\% da área do município. Foram encontrados 31 empreendimentos de extração e/ou beneficiamento mineral operando em APPs. As características das jazidas, localizadas nos trechos mais elevados dos principais alinhamentos serranos, tornam este ambiente mais favorável a extração mineral. A localização de empresas junto aos corpos hídricos e, consequentemente, em APP deve-se a grande utilização de água durante o corte das pedras. Finalmente sugere-se uma revisão da largura das APPs de Faixa Marginal de Proteção de Corpos Hídricos (FMP) de 30 metros, pois em áreas de relevo dissecado protege-se uma área maior que a necessária. Além disso, há a necessidade de estabelecer formas de mineração que não causem um impacto muito grande, principalmente nas APPs de Nascentes.

Palavras-chave: Área de Preservação Permanente. Geoprocessamento. Mineração. Erosão.

ABSTRACT: Santo Antonio de Padua municipality has quarry as one of the main economic activities. However, the mining of minerals promotes a series of environmental impacts, besides the fact that some mining companies are located in Environmental Protected Areas (APP). This article aims to map, in Santo Antonio de Padua municipality the APPs and also to identify the mining companies that operate there. In order to map the APPs we have used ArcGisR of ESRI, aerial photographs at 1:10,000 scale and IBGE cartographic basis, at 1:50,000 scale. To define the APPs we have used the concepts of resolutions 302 and 303, both from 2002, of Conama. The APPs from the top of the hills, crests, slopes over 450 slope angle, springs and river banks were mapped. The APPs represent an area of $212.28 \mathrm{~km} 2$, that corresponds to $34.78 \%$ of the municipality area. Thirty one quarry entreprises were found operating in APPs. The quarry carachteristics located on the top of the main crests, make this environment more favourable to the mineral explotation. The location of these quarry sites close to rivers and, consequently, in APPs is 
due to the great utilization of water for cutting the stones. Finally we suggest a revision on the APPS width of 30 meters, because in mountainous areas, an area larger than what is needed, is protected. Furthermore, there is the need to stablish quarry rules that do not cause a big environmental impact mainly on sprig APPs.

Keywords: Permanent Preservation Area. GIS. Mining. Erosion.

\section{INTRODUÇÃO}

O Estado do Rio de Janeiro é divido em regiões de governo, onde os municípios são agrupados em função da similaridade sócio-econômica, cultural e ambiental. Esta divisão tem como o objetivo atenuar as distorções entre os municípios. A região Noroeste, destaca-se das demais regiões por apresentar maiores disparidades ambientais e sócio-econômicas.

O município de Santo Antonio de Pádua, por possuir parte de sua economia associada a extração e ao beneficiamento de rochas ornamentais, é responsável por graves impactos ambientais nos ecossistemas. No entanto, a atividade extrativa emprega um número significativo de trabalhadores. Segundo o sindicato dos mineradores são cerca de 6.000 pessoas, trabalhando direta e indiretamente com a extração e beneficiamento das rochas.

O tamanho e a importância da extração mineral é tal que o SEBRAE considerou esta atividade como um Arranjo Produtivo Local (APL) onde são extraídos e beneficiados dois tipos de rocha: a Pedra Paduana, também conhecida com Pedra Miracema, e a Pedra Madeira, geologicamente classificadas como milonito gnaisse, que têm como característica o fácil desplacamento, possibilitando ser extraída manualmente com o auxílio de instrumentos simples (BRITO, 2004). A importância da extração mineral para a economia da cidade é muito pequena participando com apenas $0,06 \%$ do PIB municipal.

Santo Antônio de Pádua é o principal local de ocorrência deste tipo de rocha, porém materiais similares também estão presentes em Porciúncula, São José de Ubá, Itaperuna, Miracema e outros municípios da região Noroeste.

A atividade extrativa produz cerca de 500.000 $\mathrm{m}^{2}$ por mês, apesar do baixo nível tecnológico das empresas. Os principais desafios para a melhor exploração mineral estão relacionados aos impactos ambientais, o elevado nível de desperdício (a perda é de aproximadamente $40 \%$ ) e a falta de planejamento da lavra (SILVA; MARGUERON, 2002).

Diversas ações foram implementadas visando reduzir os impactos ambientais, melhorar o nível tecnológico e aumentar a renda dos mineradores. Uma das soluções implantadas foi o aproveitamento do pó-de-pedra produzido nas serrarias. Antes jogado nos rios esse resíduo é hoje em dia utilizado como matéria-prima para a produção de argamassa.

$\mathrm{Na}$ área ambiental foi desenvolvido o mapeamento das Áreas de Preservação Permanente (APPs), inicialmente no município de Santo Antônio de Pádua e posteriormente, expandido para as regiões Norte e Noroeste do Estado do Rio de Janeiro.

Este trabalho teve como objetivo identificar as áreas de extração mineral inseridas nas seguintes categorias de APP: Topo de Morro e Montanha, Linha de Cumeada, Encosta com Declividade superior a $45^{\circ}$, Faixa Marginal de Proteção de Corpos Hídricos e Nascentes. Desta forma, contribuir para o licenciamento da atividade extrativa no município de Santo Antônio de Pádua.

\section{A ÁREA DE ESTUDO}

A cidade de Santo Antônio de Pádua está localizada na região Noroeste do estado do Rio de Janeiro (Figura 1), nas coordenadas de $42^{\circ} 00^{\prime}$ e $42^{\circ} 20^{\prime}$ de longitude oeste e $21^{\circ} 25^{\prime}$ e $21^{\circ} 40^{\prime}$ de latitude sul. $\mathrm{Na}$ região as chuvas se concentram entre os meses de novembro e março. A precipitação média anual próxima a $1.150 \mathrm{~mm}$. Geomorfologicamente o município está inserido no Domínio dos Mares de Morro Florestados. Os principais rios são controlados pela 
estrutura geológica local. A vegetação original do tipo Mata Atlântica foi praticamente devastada, dando lugar inicialmente a plantações de café, algodão e cana-de-açúcar. Posteriormente estas plantações foram substituídas por pecuária extensiva, que muito contribuiu para o atual estágio de degradação das terras. Os poucos remanescentes de vegetação se restringem às áreas mais elevadas da serra Pedra Bonita, serra do Catete e serra das Frecheiras.

\section{CONTEXTO HISTÓRICO DAS ÁREAS DE PRE- SERVAÇÃO PERMANENTES (APPS)}

A conceituação das Áreas de Preservação Permanente é relativamente recente. Apesar de estar baseado no Código Florestal, este conceito somente foi difundido a partir das resoluções 302 e 303 do CO-
NAMA (BRASIL, 1965; BRASIL, 2002ab). A redação do Art. $2^{\circ}$ do Código Florestal de 1965 menciona que são de preservação permanente, as florestas e as demais formas de vegetação natural situadas ao longo dos rios, ao redor de lagoas, nas nascentes, no topo de morro, montes, montanhas e serras, nas encostas ou parte destas com declividade superior a $45^{\circ}$, nas restingas, nas bordas de tabuleiros e nas altitudes superiores a $1.800 \mathrm{~m}$. No Art $3^{\circ}$ também são consideradas de preservação permanente as florestas destinadas a atenuar a erosão, fixar dunas, formar faixas ao longo de rodovias e ferrovias, auxiliar a defesa do território nacional, proteger sítios de elevada beleza natural ou de valor científico ou histórico, asilar exemplares da fauna ou flora ameaçados de extinção, manter o ambiente necessário à vida das populações silvícolas e assegurar as condições de bem-estar público.

Figura 1: Mapa de localização do município de Santo Antônio de Pádua.

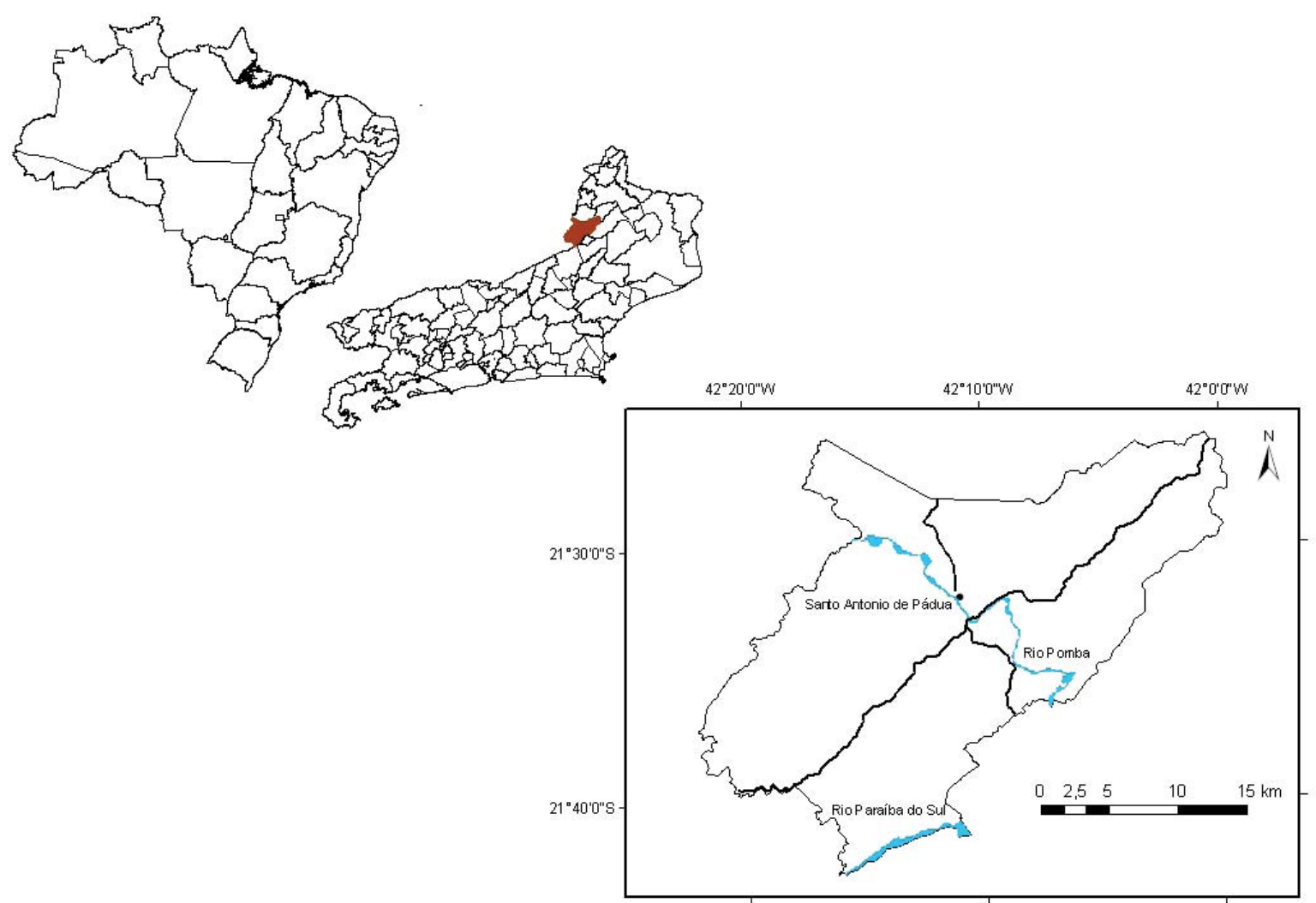

Como pode ser observado, esta lei não mencionava Áreas de Preservação Permanente, mas Vegetação de Preservação Permanente. A lei 7.803 de agosto de 1989 que alterou o código florestal também não modificou esta denominação.

A partir das resoluções Conama 302 e 303 de 
2002 o conceito é modificado para Áreas de Preservação Permanente (APPs). Nestas resoluções são estabelecidos os critérios para mapeamento de diversas categorias de APPs, pois no Código Florestal sequer apresentava os conceitos de morro, monte, montanhas e serras. A resolução 303 também introduz a categoria de APP de Linha de Cumeada, provavelmente substituindo a APP de serras presente no Código Florestal.

Apesar das extensas resoluções para normatização, os levantamentos de APPs no território nacional são escassos e irregulares. São poucos os trabalhos desenvolvidos. Este fato pode estar relacionado à dificuldade de se compreender e empregar corretamente os conceitos utilizados nas resoluções do Conama, assim como ao esforço necessário para se mapear grande áreas em escala compatível com a gestão do território.

Dentre os trabalhos desenvolvidos pela comunidade científica, pode-se citar os de Hott et al. (2004) que tinha como objetivo estabelecer métodos automatizados para determinação de Topo de Morro para o estado de São Paulo. No estado do Rio de Janeiro foram desenvolvidos alguns trabalhos de mapeamento de APPs para as regiões das Baixadas Litorâneas, Norte e Noroeste. Estes mapeamentos executados na escala de 1:50.000 representaram parte do esforço para contribuir para a gestão do território dos municípios destas regiões (SILVA et al., 2008 e SILVA, 2009). Existem outros trabalhos de mapeamento de APP, mas parte deles fica restrita a definição das APPs de margem de rios e corpos hídricos, dunas, restingas, veredas e mangues que efetivamente são mais simples de mapear.

Segundo estes autores cerca de 25 a $30 \%$ das áreas mapeadas pertenciam a alguma categoria de APP. Na área de abrangência do Consórcio Intermunicipal Lagos São João, as APPs de Topos de Morro e Montanha e Linha de Cumeada ocupam 6,6\% e 7,3\% do território, respectivamente (SILVA et al., 2008). Nas regiões Norte e Noroeste do Estado do Rio de Janeiro, a área ocupada por estas APPs é, respectivamente, $6,3 \%$ e $1,4 \%$. Os resultados obtidos por Hott et al. (2004) foram de 5,8\% para a APP de Topo de Morro e 2,4\% para a Linha de Cumeada.

Pode-se questionar que a existência de parâmetros únicos para o mapeamento das APPs produz exageros, em função das diferentes características geomorfológicas do território nacional. Por exemplo, as APPs de Faixa Marginal de Corpos Hídricos poderiam ter critérios diferentes em função da morfologia da área. As planícies de inundação ou mesmo as áreas afetadas pela água durante as cheias sazonais são completamente distintas em áreas de relevo plano a suave ondulado das áreas de relevo dissecado, como é o caso de boa parte do município de Santo Antônio de Pádua. Os rios com até 10 metros de largura em relevo dissecado poderiam ter sua Faixa Marginal de Proteção (FMP) reduzida, pois a extensão da faixa de 30 metros atinge áreas de encosta, que não são afetadas pela dinâmica das águas.

\section{METODOLOGIA}

O mapeamento das APPs consistiu inicialmente no levantamento das bases cartográficas existentes para a região. Foram utilizadas fotografias aéreas do acervo do DRM-RJ, datadas da década de 70 e do levantamento aéreo-fotogramétrico realizado em 2004 pela empresa AMPLA S/A na escala de 1:10.000. A base cartográfica utilizada foram as cartas topográficas na escala de 1:50.000 do Instituto Brasileiro de Geografia e Estatística (IBGE). Foram também utilizadas outras fontes de dados, como as cartas imagens geradas para o licenciamento das atividades de mineração em Santo Antônio de Pádua. Paralelamente, informações sobre o meio físico da região foram pesquisadas em diversas fontes, como o trabalho desenvolvido pela Companhia de Pesquisa de Recursos Minerais (CPRM, 2001) e nos relatórios finais do TAC assinado pelos mineradores e o Ministério Público Federal.

Para o controle de campo foram utilizadas as fotografias aéreas na escala de 1:10.000. Foram vetorizados todos os corpos hídricos (rios, canais, lagos, lagoas, reservatórios e áreas inundáveis). Nas vias de acesso (federal, estadual e municipal) foram vetorizados as rodovias pavimentadas, não pavimentadas, ferrovias, pontes, acessos e outros.

As diferentes cartas topográficas foram unificadas em uma única base de dados. Foi gerado o Modelo Digital do Terreno (MDT) e a partir deste foi gerada a declividade, tendo sido utilizados os seguintes intervalos: $0-17^{\circ} ; 17-30^{\circ} ; 30-45^{\circ}$; e 
acima de $45^{\circ}$. No MDT foram estabelecidos os pontos mais altos e depressões do terreno, necessários para o mapeamento de Topos de Morro e Montanha e Linha de Cumeada.

\section{Encosta com declividade superior a $45^{\circ}$}

No mapa de declividade foram destacadas todas encostas ou segmentos destas com inclinação superior $45^{\circ}$. Essas áreas constituem então na APP Encosta. Esta é uma feição que está na forma de raster, não sendo determinada a área ocupada por esta categoria de APP.

\section{Topo de Morro e Montanha}

Para a geração destas APPs foi utilizada a proposta de Hott et al. (2004). A partir do MDT gerado foram marcados os pontos mais elevados e as depres- sões. No mapa de declividade foram selecionados os cumes com mais de 50 metros de altitude em relação a base e com declividade definida pela legislação (acima de $17^{\circ}$ ), para a enquadramento no conceito de morro. Posteriormente foram selecionados os picos com mais de 300 metros de altitude em relação a base, para enquadramento no conceito de montanha.

\section{Linha de Cumeada}

O procedimento é similar aquele utilizado para delimitar topo de morro e montanha. Foram traçados segmentos da linha de cumeada equivalente a mil metros, partindo-se do pico mais baixo da cumeada - o menor morro da seqüência de morro e/ou montanhas. Foi fixada a curva de nível correspondente a dois terços da altura, em relação à base, do pico mais baixo da cumeada dentro deste segmento de mil metros, conforme modelo (Figura 2) proposto por Hott et al. (2004).

Figura 2: Esquema ilustrativo proposto por Hott et al., (2004) para a delimitação da APP de Linha de Cumeada.

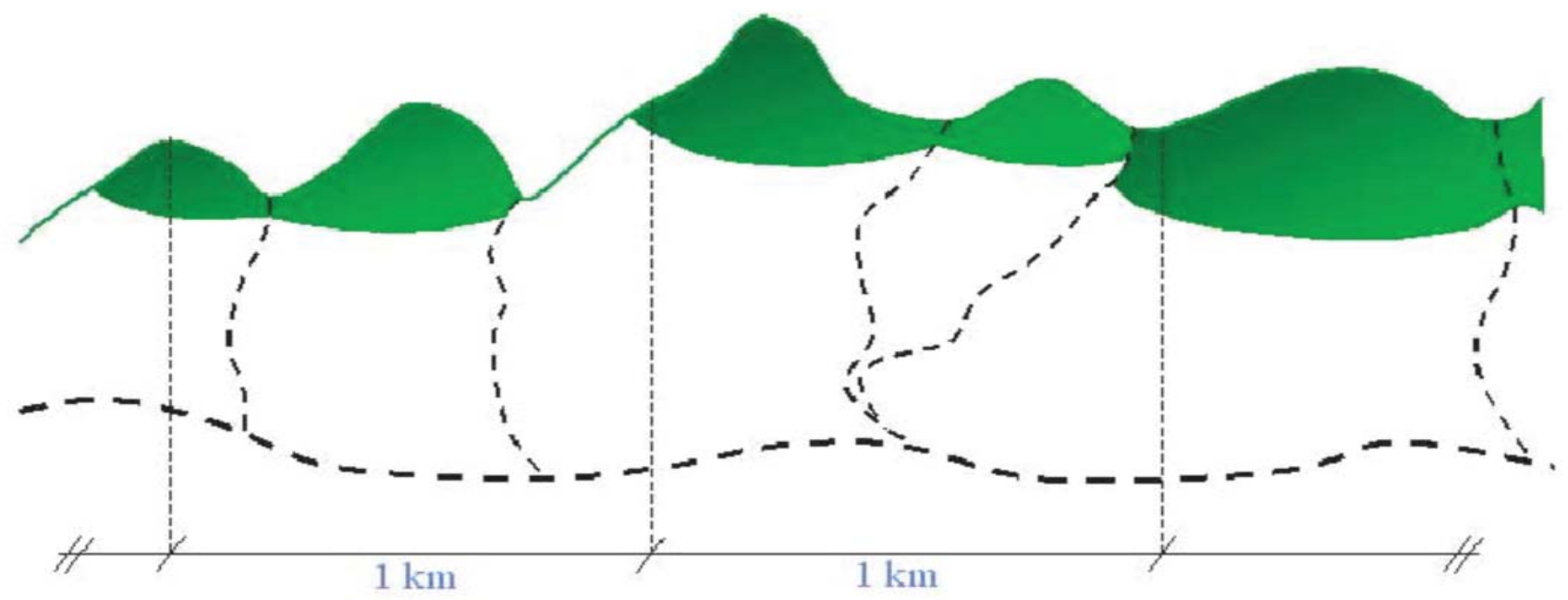

\section{APP ao redor de Nascentes ou Olho d'água:}

Para o mapeamento das nascentes foi utilizado vetor hidrografia da base cartográfica da IBGE. Foram assinalados os locais onde se iniciavam os rios e nestes foram marcadas as nascentes dos rios. A maior parte das nascentes está localizada próximo aos topos dos morros, portanto em locais de difícil acesso. A quantidade de rios que nascem na área de estudo é muito grande, demandando um tempo muito prolongado para percorrer todas as nascentes. Devido a este fato o controle de campo das nascentes foi feito por amostragem e constatou-se que todos os pontos escolhidos correspondiam a nascentes. Assim, foram separadas no banco de dados as nascentes que tiveram controle de campo, daquelas que assinaladas a partir da hidrografia. Para o estabelecimento da APP foi definido um buffer de $50 \mathrm{~m}$ ao redor de cada uma das nascentes. 


\section{APP Faixa Marginal de Cursos d'água:}

A Faixa Marginal de Proteção (FMP) dos cursos d'água foi estabelecida de acordo com a largura dos canais fluviais presentes na base cartográfica do IBGE. Para os rios de margem simples foi estabelecida uma FMP de 30 metros de largura. Para os rios de margem dupla foi feita a medição da largura nas fotografias aéreas através do $\operatorname{ArcGis}{ }^{\circledR}$. Depois de estabelecida a largura foi definida a FMP. Para rios com largura entre 10 e 50 m, FMP de 50 metros; entre 50 e 200 m, FMP de 100 metros; entre 200 e 600 m, FMP de 200 metros; e para rios com largura superior a $600 \mathrm{~m}, \mathrm{FMP}$ de 500 metros.

\section{APP Faixa Marginal de Lagos e Lagoas Naturais e Reservatórios artificiais}

O mapeamento das FMPs de lagoas e lagos foi efetuado de acordo com a resolução CONAMA 303/2000. Para a definição da FMP dos reservatórios artificiais foi utilizada a resolução CONAMA 302/2000, que dispõe sobre parâmetros, definições e limites destes reservatórios e seu regime de entorno. Para tal foram utilizadas a base cartográfica do IBGE e as fotografias aéreas da AMPLA. Foi determinada a área ocupada pelo espelho d'água e definido o buffer referente a esta área. $O$ procedimento foi similar ao adotado para a definição das FMPs dos rios.

O georreferenciamento das empresas de extração foi obtido a partir do banco de dados do DRM-RJ e das informações levantadas durante o TAC das empresas de mineração. As empresas cadastradas foram plotadas no mapa de APPs e apenas aquelas que estavam localizadas nestas áreas foram apresentadas no mapa.
Além de todo o procedimento acima descrito, foram realizados trabalhos de campo para checagem e execução de eventuais correções nos mapas gerados. A última etapa de geoprocessamento consistiu na elaboração do layout dos mapas e a impressão da carta final de APPs. Todo o trabalho foi produzido em escala 1:50.000, porém no relatório sofreu redução para 1:70.000 para fins de impressão no relatório final do projeto.

\section{RESULTADOS}

Serão apresentados os resultados obtidos assim também serão feitas algumas considerações sobre a degradação das terras.

Em 20 dias de trabalho de campo para controle das APPs mapeadas, foram marcados 88 pontos com GPS e percorridos cerca de $2.000 \mathrm{~km}$.

A Tabela 1 mostra as diferentes categorias de APPs, suas respectivas áreas e o percentual ocupado por elas no município de Santo Antonio de Pádua. Na Figura 3 podem ser observadas as distribuições das APPs no município. Das categorias de APPs mapeadas a que ocupa maior área espacial é a FMP de Cursos d'água com 17,5\%. Fato explicado por duas razões: a primeira é associada aos dois rios de grande porte (Paraíba do Sul e Pomba) que atravessam o município e em segundo lugar o relevo ondulado e fortemente dissecado.

As APPs de Topo de Morro, Montanha e Linha de Cumeada perfazem 15,5\% da área do município. Os alinhamentos serranos correspondentes a Serra do Catete, Bomfim e Serra das Frecheiras são os responsáveis pela maior participação destas categorias de APPs. 
Tabela 1: Área ocupada em $\mathrm{km}^{2}$ e em percentual das diferentes categorias de APPs em relação a área total do município de Santo Antônio de Pádua.

\begin{tabular}{c|c|c}
\hline Categoria de APP & Área ocupada $\left.\mathbf{( k m}^{\mathbf{2}}\right)$ & Área ocupada $\mathbf{( \% )}$ \\
\hline Santo Antônio de Pádua & 610,3 & - \\
\hline Topo de Morros e Montanhas & 73,8 & 12,1 \\
\hline Linhas de Cumeada & 20,8 & 3,4 \\
\hline FMP de Cursos d'água & 107,1 & 17,6 \\
\hline FMP ao redor de Nascentes & 9,2 & 1,5 \\
\hline FMP de Lagos e Lagoas Naturais & 1,3 & 0,2 \\
\hline FMP de Reservatórios Artificiais & 0,01 & 0,002 \\
\hline Total & $\mathbf{2 1 2 , 2}$ & $\mathbf{3 4 , 8}$ \\
\hline
\end{tabular}

Figura 3: Mapa de APPs do município de Santo Antônio de Pádua. Os pontos assinalados correspondem a empresas mineradoras localizadas em APPs.

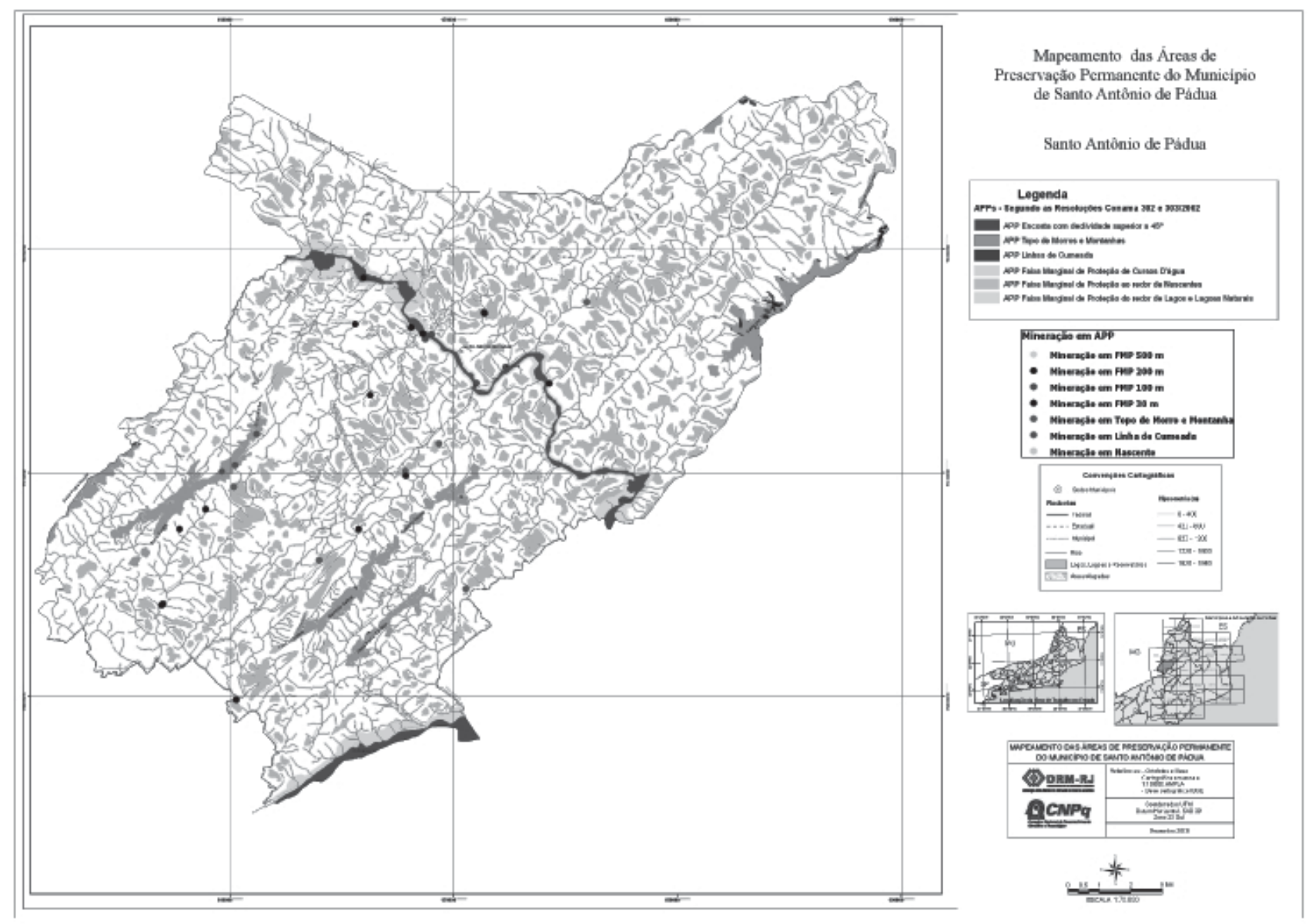


Destaca-se também a grande quantidade de nascentes. Cerca de $9,3 \mathrm{~km}^{2}$ do território municipal constituem-se em APP de nascente, correspondendo a $1,5 \%$ da área municipal (Figuras 4 e 5). Como foram consideradas no mapa apenas as nascentes presentes na carta topográfica do IBGE é possível que algumas nascentes não estejam representadas cartograficamente. Recomenda-se que quando algum empreendimento venha se instalar no local deva seja realizado um mapeamento mais detalhado das nascentes.

Figura 4: Área de nascente com recuo de cabeceira na Serra do Bonfim.

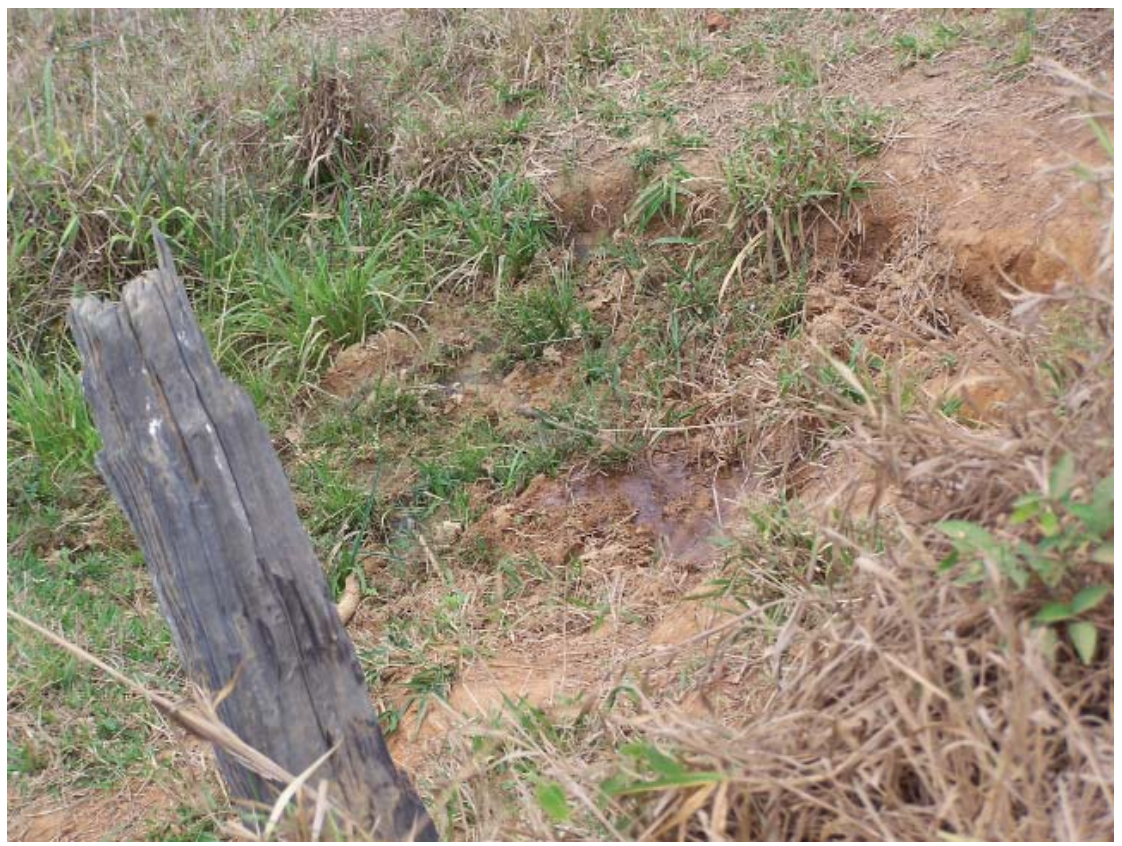

Foto: Silva, 2008

Figura 5: Nascente em cabeceira de drenagem próximo a Serra Santa Cândida.

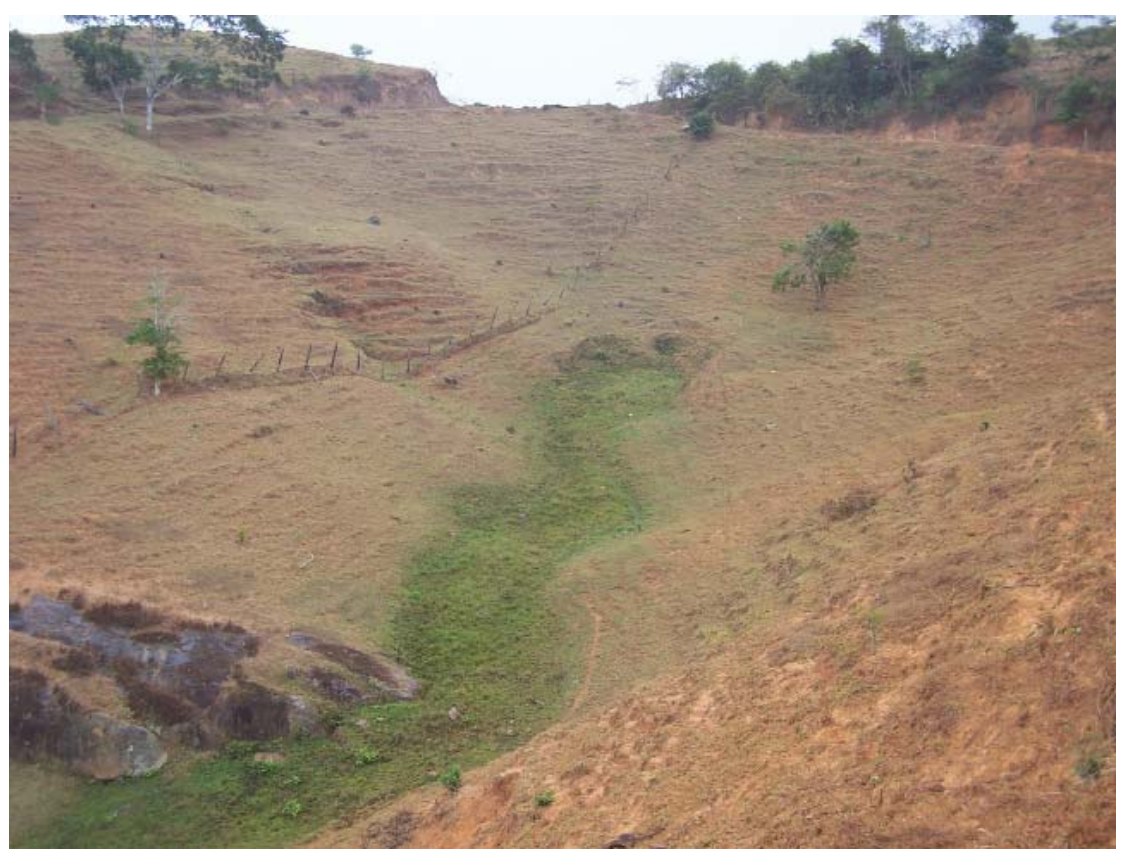

Foto: Silva, 2008

Soc. \& Nat., Uberlândia, ano 23 n. 2, 173-185, maio/ago. 2011 
Dos empreendimentos minerais existentes em Santo Antônio de Pádua constatou-se que 31 estavam inseridos em algum tipo de APP. A tabela 2 apresenta o número de empresas em APP no município. A categoria de APP que apresenta o maior número de empreendimentos mineiros é a faixa marginal de proteção de corpos hídricos com $30 \mathrm{~m}$ de largura, seguido pela APP de Topo de Morro e Montanha. Este fato está relacionado ao relevo forte ondulado e dissecado de Pádua, bem como à localização do minério nos setores mais elevados das serras do Bonfim e Catete. O elevado número de empresas que realizam o beneficiamento das rochas em APP de faixa marginal de rios, deve-se ao grande volume de água utilizado no corte das pedras. A proximidade com os rios reduz o custo com instalações hidráulicas, pois a água é bombeada diretamente de pequenas barragens construídas pelos empresários. A dinâmica espacial dos locais de extração e beneficiamento de rochas se repete em toda região Noroeste do estado do Rio de Janeiro.

A mineração de rochas ornamentais não é a única atividade desenvolvida em área de APPs. Historicamente, Santo Antônio de Pádua sofreu com práticas econômicas que exauriram e degradaram os solos. Ainda hoje é comum a prática de uma pecuária extensiva e pouco produtiva em locais onde a declividade é acentuada e principalmente em APP de Nascentes. Embora as imagens da degradação ambiental promovida pela mineração sejam visualmente mais chocantes, a prática da pecuária em áreas de preservação permanente é muito mais prejudicial aos ecossistemas, devido a dois fatores: primeiro está relacionado a grande área ocupada pela pecuária e segundo devido a forte incidência de processos erosivos provocada pela compactação do solo.

Tabela 2: Substâncias minerais e número de empresas em áreas de preservação permanente.

\begin{tabular}{|c|c|c|}
\hline Substância Mineral & Número de empresas & Categoria de APP \\
\hline Areia para construção civil & 1 & \multirow{3}{*}{ FMP $500 \mathrm{~m}$} \\
\hline Gnaisse Pedra Paduana (extração) & 1 & \\
\hline Gnaisse Pedra Paduana (aparelhamento) & 1 & \\
\hline Areia para construção civil & 2 & \multirow{2}{*}{ FMP $200 \mathrm{~m}$} \\
\hline Gnaisse Pedra Paduana (aparelhamento) & 1 & \\
\hline Areia para construção civil & 3 & \multirow[t]{2}{*}{ FMP $100 \mathrm{~m}$} \\
\hline Gnaisse Pedra Paduana (aparelhamento) & 2 & \\
\hline Gnaisse Pedra Paduana (extração) & 3 & \multirow{3}{*}{ FMP $30 \mathrm{~m}$} \\
\hline Gnaisse Pedra Paduana (aparelhamento) & 7 & \\
\hline Areia para construção civil & 1 & \\
\hline Gnaisse Pedra Paduana (extração) & 1 & Nascente \\
\hline Gnaisse Pedra Paduana (extração) & 1 & \multirow[t]{2}{*}{ Linha de Cumeada } \\
\hline Gnaisse Pedra Paduana (aparelhamento) & 1 & \\
\hline Granito ornamental (extração) & 1 & \multirow{2}{*}{$\begin{array}{c}\text { Topo de Morro e } \\
\text { Montanha }\end{array}$} \\
\hline Gnaisse Pedra Paduana (extração) & 5 & \\
\hline
\end{tabular}

São raras as nascentes que apresentam cobertura de floresta. Mesmo assim foi encontrada apenas uma ocorrência de mineração nesta categoria de APP (Figura 6). Esta pouca incidência pode estar associada ao fato de que as mineradoras estão localizadas próximo ao topo dos morros e também devido a metodologia para assinalar as nascentes. As mesmas foram assinaladas a partir de um buffer de 50 metros e as empresas foram plotadas no mapa na forma de pontos. O mapeamento de toda a área minerada ou um mapeamento de maior detalhe poderá indicar um número maior de empresas minerando em nascentes (Figura 7). 
Mineração e áreas de preservação permanentes (APPs) em Santo Antônio De Pádua - RJ Antônio Soares da Silva

Figura 6: Mineração em área de nascente.

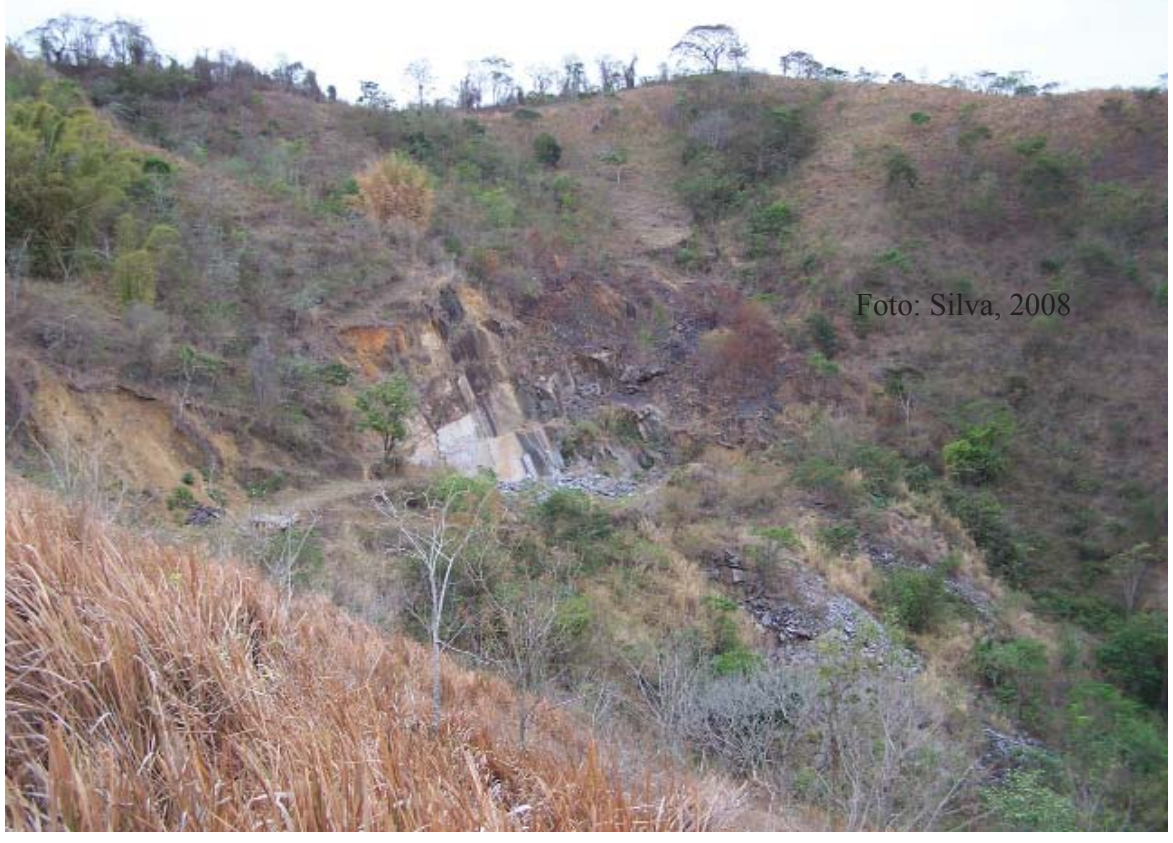

Foto: Silva, 2008

Figura 7: Utilização de nascente para deposição e descarte de estéril da mineração.

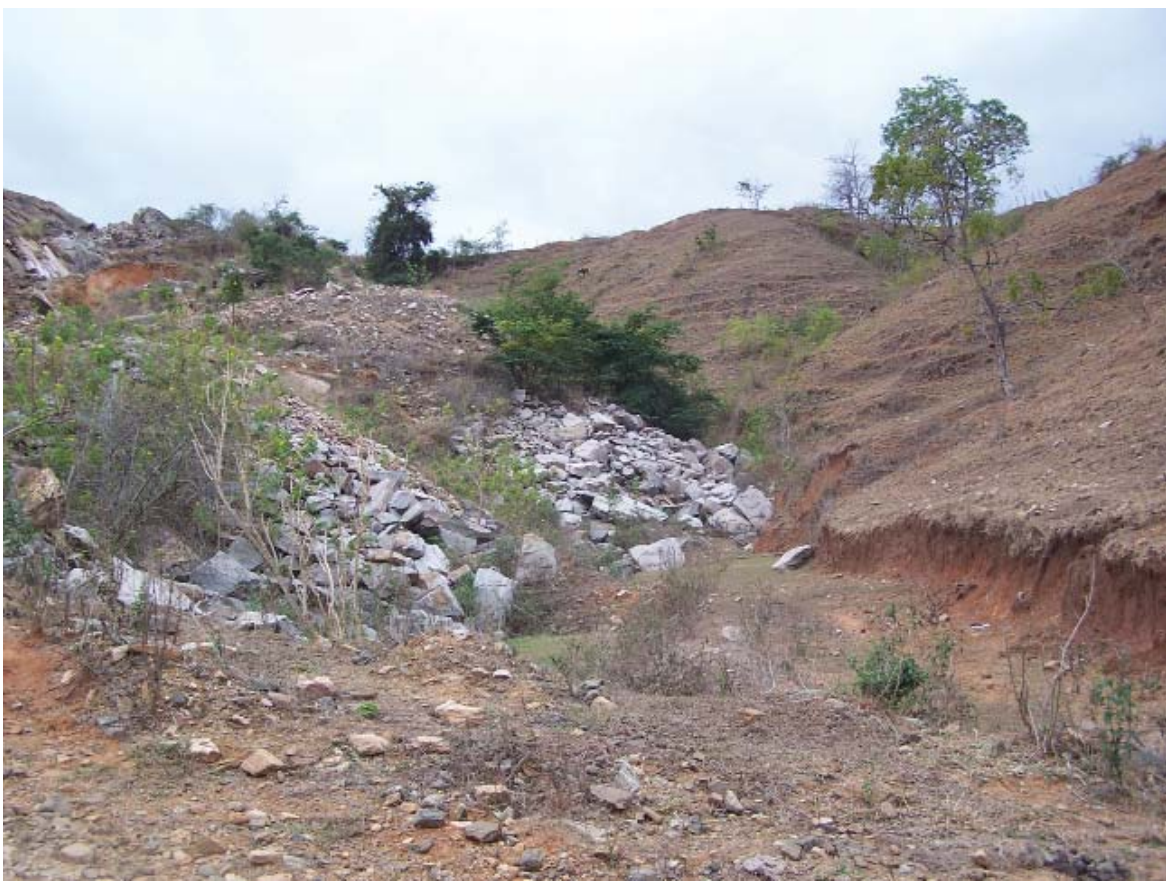

Foto: Silva, 2008

Soc. \& Nat., Uberlândia, ano 23 n. 2, 173-185, maio/ago. 2011 
Durante os trabalhos de campo também foi possível detectar a presença de diversos sinais erosivos, principalmente na forma de erosão laminar, ravinas e algumas voçorocas. Devido a elevada incidência da erosão seria indicada a elaboração do um programa de recuperação de áreas degradadas também nas locais de pastagem (Figuras 8 e 9).

Figuras 8 e 9: Sinais erosivos causados pelo pisoteio de gado em encostas com forte declividade. A passagem do gado em locais preferenciais promove a compactação do solo e criando locais preferenciais para a passagem da água, gerando formas mais avançadas de erosão, como ravinas (esquerda) e pequenas voçorocas (direita).

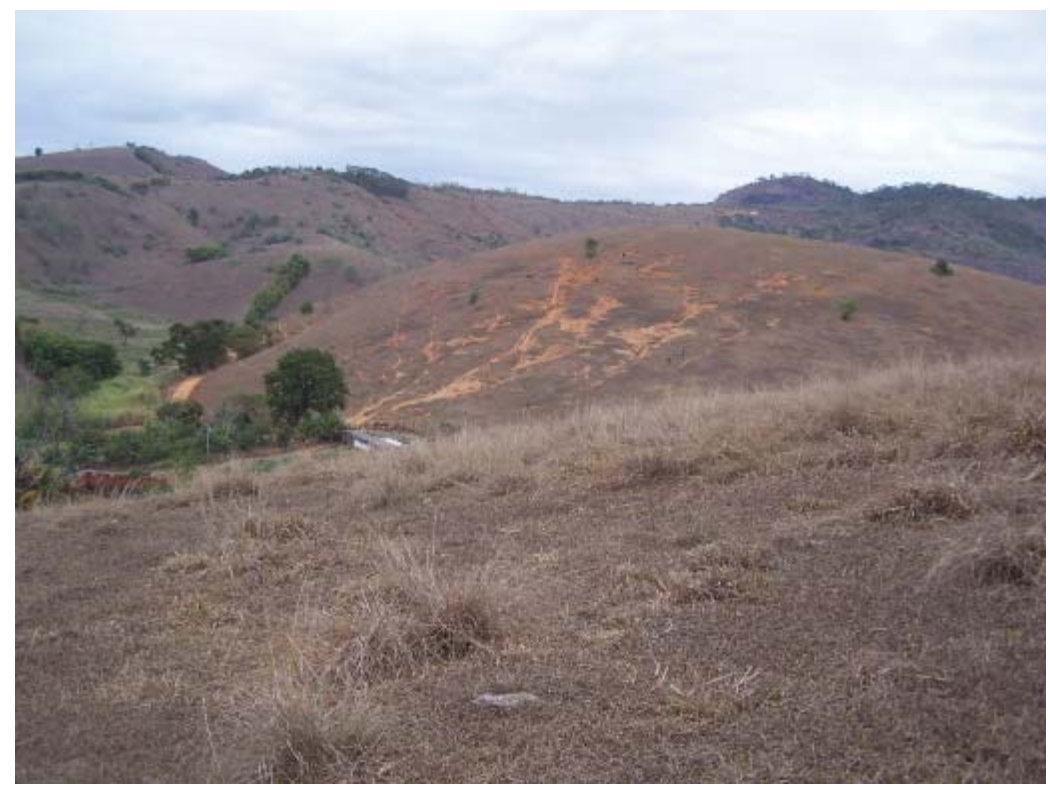

Foto: Silva, 2008

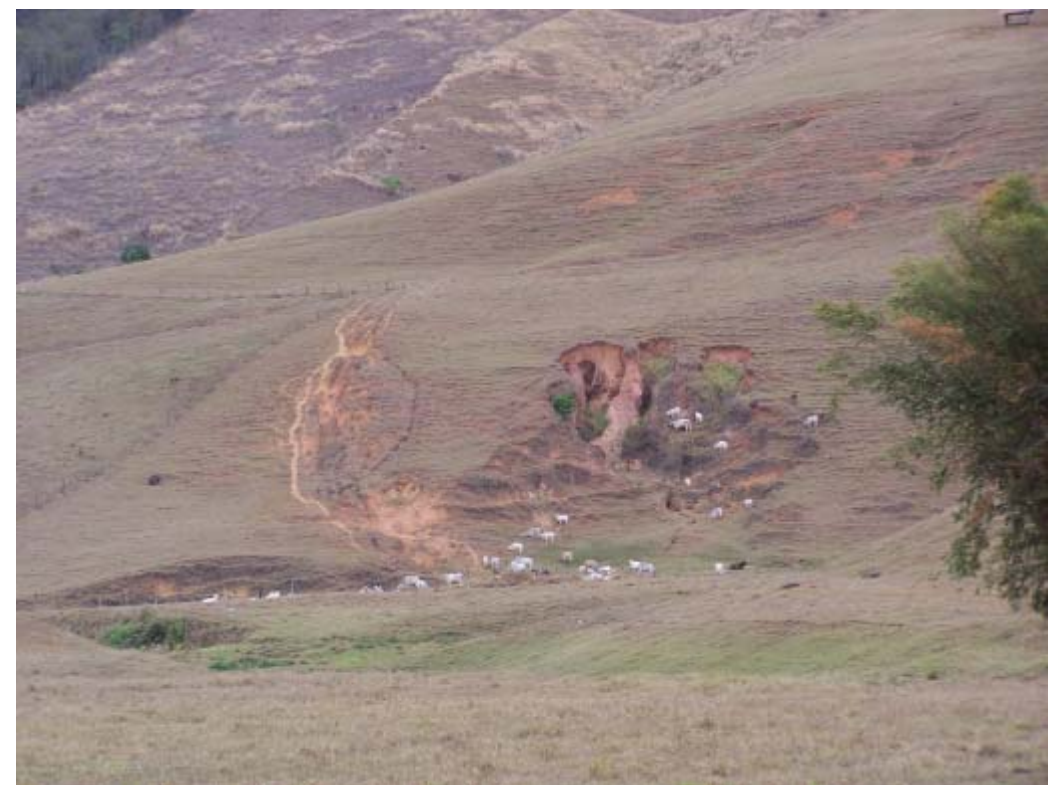

Foto: Silva, 2008 


\section{CONCLUSÕES}

A partir dos resultados obtidos pode-se perceber a importância da cartografia das APPs para a gestão do território. O licenciamento das atividades econômicas não pode ser executado sem a espacialização e o confronto com as APPs, pois os impactos destes empreendimentos sobre estas áreas poderão ser definidos com maior exatidão.

Em Santo Antônio de Pádua a área ocupada pela APP Faixa Marginal de Proteção dos Cursos d'água corresponde a uma área maior do que a imaginada. Este fato foi associado ao relevo dissecado que apresenta uma maior quantidade de canais fluviais. Cerca de $17 \%$ do território municipal corresponde a esta categoria de APP. No entanto, nas áreas de relevo dissecado das Faixas Marginais de Proteção dos Cursos d'água, principalmente as de $30 \mathrm{~m}$, poderiam ter uma menor extensão. A demarcação destas APPs em vales em "V" protege áreas que não são ocupadas pelas águas, nem mesmo durante as cheias mais elevadas.

A cartografia das APPs mostrou que o início da rede drenagem nas cartas topográficas do IBGE correspondem efetivamente as APPs de Nascentes. $\mathrm{O}$ grande número de nascentes encontradas no mapeamento está associado ao relevo dissecado, que aumenta o número de canais fluviais. As APPs de Topo de Morro, Montanha e Linha de Cumeada ocupam juntas cerca de $15 \%$ do território municipal.

Algumas nascentes apresentavam um grande volume de água mesmo durante a estação da seca. Estes locais merecem estudos mais detalhados onde poderiam ser avaliadas a vazão e a qualidade da água destas nascentes, uma vez que as mesmas se constituiriam em fonte de água para consumo por parte da população rural.

Finalmente, mineração e prática da pecuária em APP podem representar ou mesmo serem responsabilizadas pela perda da qualidade ambiental. Estas áreas podem contribuir com uma carga de sedimentos bem maior do que aquela que os rios podem transportar.

O impacto visual da mineração é muito forte, mas a erosão provocada pelo pastoreio excessivo, principalmente quando esta se apresenta na forma de ravinas e voçorocas causam mais degradação ambien- tal do que a mineração. A erosão laminar, mais comum, é pouco visível e talvez por isso não se dê a devida atenção para este processo. É comum a presença de solos com o horizonte B (avermelhado) à superfície.

\section{AGRADECIMENTOS}

Ao Conselho Nacional de Desenvolvimento Científico e Tecnológico (CNPq) pela concessão de apoio financeiro ao projeto. Ao DRM-RJ pelo suporte logístico. Ao geólogo Ricardo Sodré pela participação nos trabalhos de campo.

\section{REFERÊNCIAS}

BRASIL. Lei 4.771, de 15 de setembro de 1965. Código Florestal, Brasília, DF. Disponível em: <http:// www.planalto.gov.br/ccivil_03/Leis/L4771.htm>. Acesso em: 15 set. 2010.

BRASIL. Ministério do Meio Ambiente. Conselho Nacional do Meio Ambiente. Resolução 302 de março de 2002(a). Disponível em: <http://www.mma.gov.br/ port/conama/res/res02/res30202.html>. Acesso em: 14 fev. 2007.

. Resolução 303 de 20 de março de 2002(b). Disponível em: < http://www.mma.gov.br/port/conama/ res/res02/res30302.html>. Acesso em: 14 fev. 2007.

BRITO, J. Arranjos produtivos locais: perfil das concentrações de atividade econômicas no Estado do Rio de Janeiro. Rio de Janeiro. SEBRAE/RJ, 2004.

CPRM. Ministério das Minas e Energia. Programa Levantamentos Geológicos Básicos do Brasil - Geologia do Estado do Rio de Janeiro. Rio de Janeiro. 2001. CD-ROM.

HOTT, M. C.; GUIMARÃES, M.; MIRANDA, E. E. Método para determinação automática de áreas de preservação permanente em topo de morro para o Estado de São Paulo, com base em Geoprocessamento. Documentos. Campinas, n. 34. 2004. Disponível em: http://www.cnpm.embrapa.br/publica/download/ doc34_AAAPTM04.pdf. Acesso em: 15 set. 2010. 
SILVA, A. S. Relatório do projeto Mapeamento das áreas de preservação permanentes das regiões norte e noroeste do estado do rio de janeiro como subsídio à gestão do território. 15p. 2009.

SILVA, A. S.; MANSUR, K. L.; PAULA, V. M.; FERREIRA, A. P. S. Mapeamento das Áreas de Preservação Permanente como subsídio à gestão do território. Geografia: Ensino \& Pesquisa. v.12, n 1 , p. 2261 - 2275, 2008. 1 CD-ROM.

SILVA, R. E. C.; MARGUERON, C. Estudo Geológico-Técnico de uma pedreira de rocha ornamental no município de Santo Antônio de Pádua - Rio de Janeiro. Anuário do Instituto de Geociências - UFRJ. v. 25, p. 125-150. 2002. 